\title{
LA GESTACIÓN DE IMÁGENES DEL MESTIZO EN EL PENSAMIENTO ARGUEDIANO
}

\author{
CARLOS MIGUEL SALAZAR \\ Universidad de Roma «La Sapienza» (Italia) \\ Carlos.Salazar@uniroma1.it
}

\section{RESUMEN}

En este artículo planteo un caso de negación simbólica del valor cultural de J. M. Arguedas y después examino algunos significados de la categoría de «mestizo»; una noción central y vinculada tanto a sus escritos literarios como sociales. Por eso, es interesante analizar algunas imágenes sobre el mestizo plasmadas desde el principio en su narración considerada indigenista, la cual se transforma en narración «total» en sus últimos trabajos. De la imaginación etnológica de Arguedas nos han llegado nociones cada vez más nítidas de un discurso social comprometido, en el cual se distinguen los protagonistas indios, mestizos y señores en relación a la sociedad y economía o a las artes y la música. También se discuten las acepciones y matices sobre el mestizo que se modifican, sin suponer esquematismo alguno. Mi lectura distingue diferentes representaciones del mestizo ficcional e histórico, ambos forjados e identificados en la construcción de su entera narración. El mestizo es seguramente una de las categorías que nos ofrece una comprensión mejor del valor de la identidad actual en los Andes.

Palabras claves: Figura literaria, mestizo, personaje híbrido, construcción identitaria.

\section{ABSTRACT}

In this paper I present a case of symbolic denial of the cultural value of J. M. Arguedas and, then, I examine some meanings of the category of mestizo: a central concept related to both his literary and social writings. It is therefore interesting to analyze some images of the mestizo, forged from the beginning in his narrative considered indigenista which becomes a «total» narration in his last works. In the ethnological imagination of Arguedas, the discourse gets more and more socially committed where its protagonists -indios, mestizos and lords- are defined in relation to society and economy or arts and music. I further discuss the meanings and shades of the mestizo representation reinvented continuously beyond any schematism. My reading distinguishes different perceptions of the ficcional and historical mestizo, both formed and recognized in the construction of his entire narration. The mestizo is definitely one of the categories that offer us a better understanding of the value of modern identity in the Andes.

Keywords: Arguedas, mestizo, modern identity, literary and social writing.

Una primera aproximación a la categoría de «mestizo» en el universo narrativo arguediano, nos indica que se trata de una temática desigual y gradualmente construida, dado que en la escritura de Arguedas cohabitan varias figuras e individuos secundarios $\mathrm{y}$ protagonistas a los cuales se le podría aplicar este calificativo. El cuadro de nuevos sujetos
Carlos Miguel Salazar

Zagazeta

Es doctor en Ciencias Etno-Antropológicas por la Universidad «La Sapienza» de Roma y profesor de Español de la cátedra de Lenguas y Literaturas Hispanoamericanas de la Facultad de Ciencias Humanísticas. Nació en Lima y vive en Roma desde hace veinticinco años donde enseña y ha investigado sobre la interculturalidad y el sincretismo del discurso colonial de los siglos XIV y XVII. Especialmente ha trabajado las crónicas del Inca Garcilaso de la Vega y Guamán Poma de Ayala, que han dado lugar a diferentes cursos universitarios. Se dedica también a la narrativa de J. M. Arguedas frente a los indigenismos andinos, además de estudiar la literatura del «tiempo del miedo», empezando por las novelas de $\mathrm{Mi}$ guel Gutiérrez y Daniel Alarcón, para continuar con los cuentos y ensayos sobre la violencia peruana. Es autor de Frammenti andini. Gli insegnanti di Cuzco reinventano un'identità nazionale (2010) y coautor de Sincretismos heterogéneos. Transformación religiosa en América Latina y el Caribe (2011). Entre sus más recientes ensayos se encuentran ¿Comentarios reales o inventados? Los profesores cus queños tienen la palabra (2006); La transformación del culto de la Pachamama y la protección de la Madre Tierra (2012), además de No una sino muchas Limas (2012).
La gestación de imágenes del mestizo en el pensamiento arguediano

CARLOS MIGUEL SALAZAR 


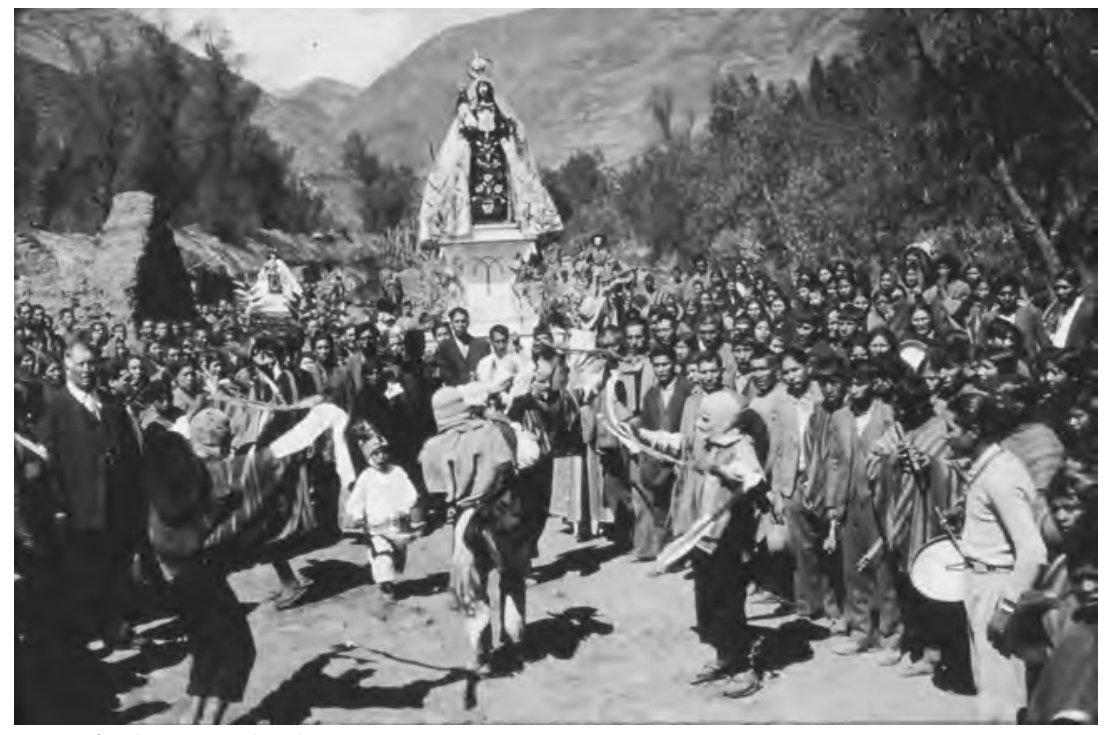

Fotografía de Martín Chambi débil, ambiguo o replegado. Conductas que justamente cambiarán en sus textos sucesivos donde el personaje, sus relaciones y hasta su condición étnica pueden variar en el caso de la narración literaria que forjará el «mestizo ficcional», lo mismo que en el caso de su rica narración antropológica que impulsará el «mestizo histórico» en torno al cual se focaliza este ensayo.

Entre estos se hallan los personajes que cobran gradualmente preponderancia, mientras que en el caso de sus estudios sociales el mestizo, más bien, hará referencia a figuras históricas que encuentran individual o colectivamente anunciando la transformación de su vulnerabilidad. Éste se convierte en el sujeto que proyecta una sociedad que parece cobrar vida en el proceso de transculturación, bajo condiciones de poco peso del pasado colonial y mayor libertad económica. El estudio de figuras símiles ilustradas en algunos momentos de su producción periodística juvenil, permitiría señalar construcciones imaginarias bastante bien logradas hasta la conseguida sobre personajes con nombres propios y en los que se convierte en migrante colectivo. Arguedas abandona de este modo la idea de un mestizaje nacional sin asidero en la realidad que habría mantenido a los mestizos como subalternos y desintegrados.

Distingue entonces el espacio identitario del mestizo, aun cuando aparece como protagonista anónimo y marginal o secundario y principal. Igualmente lo hace en su explicación como personaje colectivo y en relación a su dinamicidad sociocultural de la sierra central y sur, interesándose en la producción artesanal, musical y artística que coinciden con los años de su madurez profesional. La intuición arguediana y la capacidad de elaborar un mensaje claro sobre la profunda interioridad de indios, mestizos y señores -no obstante admitiese con dificultad la condición mestiza de sí mismo- prueban la dificultad de definir culturalmente individuos a los cuales se les agrega como si fuera innata y no cultural la índole o la conducta «fluctuante» de la figura en estudio: el aculturado por excelencia.

\section{1. ¿Ocaso de un visionario de la cultura?}

Hoy reconocemos que el discurso sobre la nación en el Perú tiene la necesidad de recoger las ideas de diferentes pensadores, desde 
una perspectiva menos triunfalista y más cuidadosa de las fronteras de reflexión sobre la heterogeneidad cultural, no sólo por sus aspectos sociales e históricos sino también antropológicos.

Pasó la época de una comunidad nacional construida a partir de héroes de vocación patriótica y de difícil comprobación historiográfica, de un tiempo republicano en el que se pensaba necesario tener mártires a los cuales dedicar un sentimiento de amor al territorio, valores, símbolos y antepasados ilustres. Terminó también el tiempo de los estados monolingües con una sola cultura, que hiciesen parte de una única nación. Los discursos de afirmación identitaria a favor de la pluralidad étnica de Bolivia y Ecuador, hacen pensar en un cambio de marcha que los peruanos todavía no damos, ya que seguimos los esquemas viejos y protagonismos proclives a la trivialidad criolla. ¿Un último ejemplo? Hace dos años se optó oficialmente por llamar el 2011 «Año de la revelación de Machu Picchu» y no del «Centenario del nacimiento de Arguedas»1. Ganó una visión monumentalista y museal, correspondiente al dominio identitario criollo que divulga todavía el «mito del Perú» y se lucra de la imagen del «país de la maravilla». Una ocasión perdida que indica una caída humillante del Arguedas integrador de las patrias y de la refundación del Perú moderno a partir de sus textos y empeño institucional, y seguramente del rechazo a la exclusión de los indígenas y de su cultura serrana.

Este trabajo es una reflexión, una entrada crítica de la relación entre la narración y el ensayo de Arguedas, poeta indispensable de la literatura heterogénea peruana, considerando su claridad y contrariedades en la elaboración y el uso de razones que «durante los últimos cuarenta años [ha concurrido] a la expansión, complejización y sofisticación del área andina como espacio crítico simbólico, [donde] han convergido [diferentes ideas de cultura], a pesar de la diferencia y diversidad de los marcos críticos e ideológicos desde los cuales se enuncian» (Rivera, 2011, p. 60). No está demás insistir en que esta reinvención del espacio cultural y del registro lingüístico, basado en la oralidad -si no inédito, enriquecedor en la acepción de la pluralidad identitaria- se ha vuelto un lugar de individualización de la «proeza artística» que, como novela real maravillosa, bebe de las fuentes orales, musicales y épicas (González Vigil, 2000 , p. 60). Además de los hondos desencuentros que no deben olvidar la defensa de la trilogía Mariátegui, Vallejo y Arguedas, como fundadores de un imaginario moderno y de la vitalidad de la pluralidad sociocultural (Portocarrero, 2005).

Por esto, aprovecho para resaltar el tema que puede hacernos pensar en el ocaso del imaginario plural de Arguedas, o bien en la pérdida gradual de su legado que deberíamos actualizar siempre más allá del círculo de estudiosos $^{2}$, para no reducirlo a mera conmemoración ritual. Hay que recordar la vocación del mismo autor, quien hizo un «experimento educacional» desde su primer trabajo de docente en Sicuani, enfrascado en su tarea de enseñanza y divulgación directa a los niños y jóvenes (Rowe, 1996, p. 22). A despecho de la negación oficial aludida ${ }^{3}$, puedo decir que durante mi investigación en las escuelas secundarias de Cuzco encontré una imagen positiva de Arguedas, ya que muchos docentes se esmeran para acercar a los jóvenes a la lectura de sus cuentos iniciales (Salazar, 2006; 2010 , p. 114 $)^{4}$. Lo reitero porque es importante insistir en la utopía arguediana del «país diverso", para que en las aulas se aprovechen sus narraciones sobre las raíces culturales y se entiendan la alegría, tristeza y belleza de sus figuras, ahora que se conoce la existencia de áreas de subalternidad y negación.

\section{Certezas del espacio arguediano}

Hoy descubrimos que este discurso contiene mensajes imprescindibles y ello es parte de una obra unitaria compuesta por la escritura literaria y etnográfica que tuvo lugar cuando finaliza el positivismo, que permite a Arguedas conjugar ambas percepciones e ilustrar su realidad sociocultural (Rowe, 1996, p. 19). Por otra parte, aparece su modo realista y la revaloración del pueblo quechua que «crea cantos y mitos» (Arguedas, 1973, p. 297) y, en particular, que comienza en el microcosmos de la comunidad rural hasta llegar al macrocosmos nacional.

Arguedas personifica entonces figuras que desde la aldea se materializan y ocuparán papeles protagónicos en la sociedad moderna donde componen imágenes de un interés identificado con los indígenas. Intereses que
1

Se pueden ver videos en Youtube que constatan varias opiniones $y$ el juicio positivo de Vargas Llosa. No sé si pesaba más la ideología del partido de gobierno en el fallo, lo cierto es que señala el desdén de la obra arguediana asociada al universo cultural andino y popular.

2

Una relación análoga existe en Italia con la obra de Antonio Gramsci. Sus Quaderni del carcere dan pie a conceptos e hipótesis interpretativas que retoman sus «recorridas» ideas, por encima del uso clásico de as izquierdas. Auspiciar la validez de la propuesta arguediana en la modernidad es una tarea indispensable que se aúna al conocimiento de sus textos literarios.

3

La polémica sobre el lema demuestra también la indiferencia de las cumbres ministeriales, así como la voluntad de no aceptar los varios orígenes, lenguas y etnias de la población.

4

Creo que existen actividades ligadas estrechamente a la difusión del pensamiento arguediano entre niños y jóvenes peruanos. Talleres de narración y encuentros a este propósito fueron justamente realizados en 2004, como lo cuentan los miembros del Seminario Carla Sagástegui en la presentación de trabajos y, en especial, Gonzalo Portocarrero en su texto (2005). No obstante, estos eventos hechos con "cariño y esmero» deberían promoverse por los maestros e intelectuales con regularidad y en todo el ámbito nacional.

\footnotetext{
La gestación de imágenes del mestizo en el pensamiento arguediano

CARLOS MIGUEL SALAZAR
} 

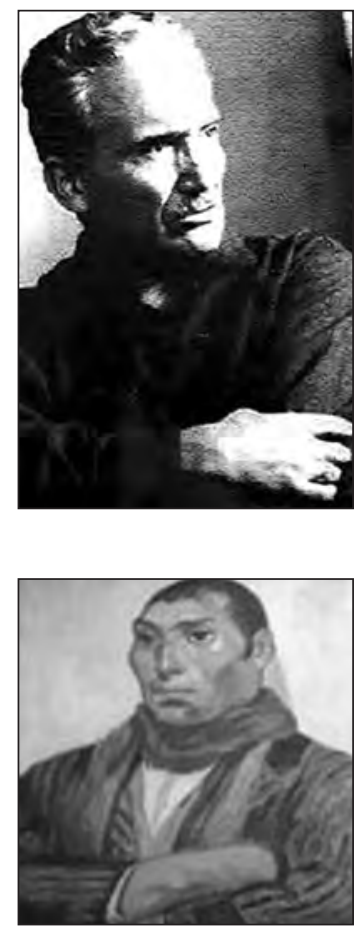

El recluta. José Sabogal

5

La afirmación de Arguedas en relación a la revista de "orientación doctrinaria» es clara: "Allí descubrimos gran parte del mundo interior del pueblo indígena, el mestizo y aún de los señores, a quienes no les negamos la posibilidad de contribuir también en la construcción del gran Perú» (Pinilla, 1993).

6

Hay que recordar que el Inca Garcilaso de la Vega afirmó en los Comentarios ser mestizo y fruto del encuentro armónico de dos razas y pueblos, asegurado por el pensamiento renacentista y su fe. En otra obra afirmó ser indio y en otra defendió igualmente su linaje hispánico. Una pista sobre la afirmación identitaria, que es un ejemplo de postulado discursivo en base al neoplatonismo que también se proyectó en el mestizaje peruano.

La gestación de imágenes del mestizo en el pensamiento arguediano

CARLOS MIGUEL SALAZAR le sirven para entender también el dinamismo del desarrollo en el valle del Mantaro en su perspectiva social y cultural, pero, sobre todo, musical y artesanal, hasta convertirlas en el espacio privilegiado del mestizaje (Fell, 1991). Ésta es una situación que trata en $L a$ sierra en el proceso de la cultura peruana (1954) y en otros ensayos sobre las comunidades del Valle del Mantaro, donde oponía los interlocutores mestizos, uno de ese valle y el otro atribuible a la realidad ayacuchana (1981, pp. 9-27).

Pero las ideas de Arguedas no eran superficiales o simplemente culturalistas, ya que reconocían plenamente el análisis de clase y la existencia de diferencias étnico-lingüísticas, lo que le permitía plasmar en sus ensayos antropológicos una interpretación sobre el pasado y presente andino y del Perú. Interpretación incluso biográfica que en la Mesa redonda de 1965 enuncia con una voz herida: «voy a confesar que hay algunas cosas que no son exactamente etnográficas» (VV.AA., 1985, p. 36).

El hecho de narrar personajes y región olvidados le ofrece la posibilidad de recrear esa realidad con elementos innovadores lingüísticos y estéticos. Inventa así un modo diferente de narrar la escisión entre indígenas y españoles, originada por la invasión y revivida en el Perú del siglo XX a través de una gama de distancias socioculturales y fisuras traumáticas. En ellas es posible insistir en la división entre indios y blancos, superpuesta a la división de clases que entretejía otras distancias esenciales que ilumina magistralmente. La escisión entre el limeño y el provinciano, el patrón y el sirviente, el jefe y el subordinado e incluso el hombre y la mujer (López Maguiña y Portocarrero, 2004).

En la estructura narrativa, sus personajes personifican las fracturas del orden social y sobrellevan las diferencias materiales y simbólicas, junto a las heridas que no eran sólo el amor o el rencor de los subalternos sino los artificios explicativos de la cohabitación que los superaba. Claro está, sin abjurar de las desigualdades y genialidades que en su escritura alcanzó para hacer conocer las oposiciones de su universo literario y de una realidad conflictiva (Forgues, 2004, p. 106), ignorada aún por muchos peruanos en la primera mitad del siglo XX.
Me he preguntado cómo se podía imaginar el concepto del mestizaje no sólo en la primera parte del siglo pasado, sino en un país en el que el ciudadano todavía se encuentra enmarañado en exclusiones y racismo que conducen a la pigmentocracia y a entrever la problemática de la superioridad étnica. Admitiendo el hecho de que su aplicación hoy es inaceptable, no podemos dejar de reconocer que persisten las injusticias, las discriminaciones, la violencia y una hegemonía monocultural después de varios decenios del lúcido mensaje arguediano (Callirgos, 1993 p. 211; Manrique, 1995). Como ha identificado Del Pino, añadiría que Arguedas entre otras virtudes estratégicas, mantuvo una percepción personal de amplio respiro por su experiencia de vida, a la que puede integrarse el «realismo lingüístico» que conjugó el mejor quechua con el castellano como expresión intercultural. Aparte, desplegó un indiscutible «dominio literario» que seguía los cambios y el conjunto de transformaciones socioculturales y políticas (Del Pino, 2005).

Arguedas no pensaba que los indios, mestizos o mistis fueran sustitutivos de las clases sociales. Su preocupación central empezaba, más bien, a partir de la «cuestión indígena» y es lo que lo confronta permanentemente con el indigenismo más romántico de la denuncia que encontraba un asidero precioso en el segundo de los siete ensayos que compuso Mariátegui, concebido durante los años veinte del siglo pasado ${ }^{5}$. Su interés también se desplazó al mestizo, o bien, al dominador dominado que soportaba el odio de los indios $\mathrm{y}$ el desprecio del terrateniente (Forgues, 2004, p. 115).

Esta premisa está en relación directa al mestizaje que incorpora la situación existencial de Arguedas, exigiéndonos revisar otras enunciaciones similares ${ }^{6}$. Es una tarea que asume el riesgo de reducir su pensamiento, que fue suscitado en contrapunto a otros y según ideas que deben contextualizarse para no identificarlas como meras huellas aisladas.

\section{El espacio de reflexión del mestizo en las escritura arguediana}

Si bien Arguedas emplea en sus relatos y ensayos la imagen del mestizo esmeradamente, desde la primera hasta El zorro de arriba y el zorro de abajo (1971), existe un uso mayor 
en la primera fase en la que los personajes híbridos «no tienen mucho espacio en [un] mundo que no permite las situaciones intermedias» (Flores Galindo, 1988, p. 353). En efecto, esta convicción es posible aplicarla a la infatigable pluma arguediana hasta 1958, cuando el autor responde más a sus tensiones existenciales que a los logros de la antropología. Sin embargo, pesa significativamente la aseveración de Nelson Manrique que para ese primer periodo confirma que «en el mundo escindido entre mistis e indios no hay lugar para los mestizos» (1995).

Estos criterios apenas citados me permiten subrayar que Arguedas alimentó opiniones indispensables pero desiguales sobre el «mestizo», según un crecimiento original no sólo profesional sino emotivo y político. Asimismo me permite enfatizar otras relaciones que a continuación expongo breve y cronológicamente, sobre todo, en los momentos de mayor importancia de esta cuestión. Debe quedar claro que Arguedas razona sobre el mestizo a través de sus personajes literarios e, igualmente, va nutriéndose de definiciones que van desde las ideas de sentido común para luego servirse de aproximaciones histórico-culturales bastante delicadas. Con todo, sus figuras literarias e históricas asumían la condición del mestizo bajo su personal enfoque creativo y el análisis lingüístico y folclórico-antropológico.

Un punto hermenéutico clave puede fijarse en el decenio de los cincuenta y extenderse a la primera parte de los sesenta, cuando Arguedas decide la centralidad de algunas cuestiones a través de artículos y, pocas veces, de textos extensos. Este interés se concentra en la antología arguediana Formación de una cultura nacional indoamericana de Ángel Rama, donde reúne sus ensayos etnológicos y folclóricos «ejemplares» y fija sus derroteros: las comunidades indígenas, el arte popular religioso, el pueblo indígena de Puquio, la cultura mestiza y la región serrana, la defensa de las culturas autóctonas y el citado enfoque crítico sobre el indigenismo, además de ritos, mitos y fiestas de los pueblos. Argumentos ligados al interés que mantuvo por un enfoque que iluminase los cambios en la sociedad de los Andes y donde se podía identificar una relectura del Perú que dialogase con sus textos literarios. Algunos avances sobre la construcción identitaria se hallan con frecuencia envueltos en el sumario apenas citado y en otras antologías que reúnen sus artículos, comenzando por sus obras completas y otros materiales todavía dispersos.

En el ensayo sobre El complejo cultural del Perú (1952), puede afirmarse que Arguedas define la importancia del estudio sobre el mestizaje y el papel emprendedor del mestizo, elaborando un marco conceptual para el debate cultural que parecía corresponder al país. Como parte del período que «deja de ser indigenista» ${ }^{7}$, Arguedas hace un comentario definitivo en el sentido de una percepción indispensable:

El conocimiento del mestizo es esencial para la buena orientación de todas las actividades nacionales en el Perú. La educación, la sanidad, la producción, los cálculos acerca de las posibilidades y el destino del país (1981, pp. 1-8).

En este texto breve, Arguedas justifica la urgencia de investigar el mestizaje y el conjunto temático relacionado que se habría modificado a partir de los cambios que componían la figura histórica de su figura central, dadas las transformaciones socioculturales que el modelo económico determinaba. Igualmente propuso algunos espacios en los que encontró al mestizo vinculado al desarrollo modernizador que habría provocado, también, un futuro proceso de integración social e, igualmente, diferentes grados de mestizaje. Por esto, exigía mayor interés, porque:

hasta el presente sólo se han escrito ensayos que contienen reflexiones sobre el problema; no se ha cumplido aún un verdadero plan de investigaciones en contacto con el hombre mismo [...]. El mestizo es el hombre más debatido del Perú y el menos estudiado. Naturalmente no tomamos en consideración a quienes niegan su existencia. No bastará, para los fines de este artículo, señalar que hay infinidad de grados de mestizaje; que es muy distinto el que se forma en los pueblos pequeños de la sierra y el que aparece en las ciudades, que en lugares como Ayacucho y Huaraz, pueden encontrarse mestizos apenas diferenciados del indio y del tipo que podríamos llamar representativo del hombre asimilado a la cultura occidental (ibíd.).

Quisiera recordar que en este mismo ensayo Arguedas cita a L. E. Valcárcel, indi-
Como narrador, Arguedas no se siente parte del indigenismo y deja el contexto de la comunidad indígena para asumir la narración de la «totalidad del país», como lo expresa indirectamente (Arguedas, 1989b). Es más apropiada la noción de neoindigenismo para definir el conjunto de su obra literaria (Rovira, 2001). 


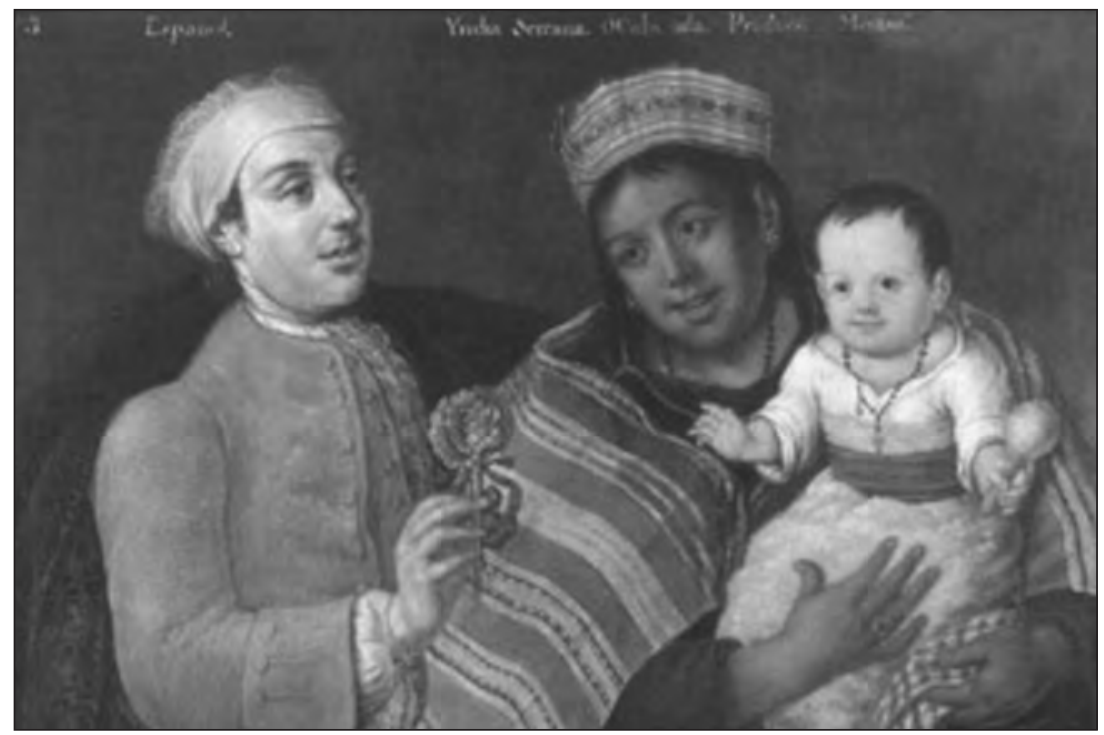

De español e india, mestizo. Cuadro de Castas encargado por el virrey Amat hacia 1770

8

Su aversión total es similar a la de Guaman Poma, por citar también al segundo ilustre cronista que consideraba necesaria la conservación de las razas originarias frente a un mestizaje racial que, desde el punto de vista de su defensa indígena, rompía la percepción del mundo propia y europea.

La gestación de imágenes del mestizo en el pensamiento arguediano

CARLOS MIGUEL SALAZAR genista de la primera hora, quien no escondía su hostilidad hacia la figura del mestizo. Observándolo, Valcárcel construía un personaje «traicionero» que absorbía el «rechazo de los de arriba y los de abajo ${ }^{8}$, con tantas limitaciones que no proyectaban salida alguna. De él se expresa con tono áspero:

no ha cristalizado, no ha podido cuajar sino apenas como borroso elemento de la clase media [...], padece la tragedia de dos almas irreconciliables y el doble rechazo de los de arriba y de los de abajo [...] los indios de las ciudades y los indomestizos (mestizos con predominio indio) son, en nuestro tiempo, los yanakuna de los incas, desertores de la comunidad, desarraigados del terruño, fuera del cobijo y protección del grupo, de la gran familia (ibíd.).

En esta primera confrontación el criterio pragmático de Arguedas es renuente a reducirlo a «un borroso elemento de la clase media». Por esto no sorprende el deslinde con el «pesimismo» con el que se refiere a Valcárcel, ya que enfrenta el aspecto más desfavorable que encuentra a un fenómeno que lo entendía como «realidad innegable» en los pueblos de las provincias del Mantaro y de Cuzco. Seguramente Arguedas consideraba auténtica su experiencia por la que los mestizos, a pesar de sufrir el «doble rechazo» en la realidad social, podían interactuar con simplicidad junto a los indios, sin renunciar a su capacidad de proceder de diferentes maneras $y$, excepcionalmente, comprometiéndose. Claro está, sin ocupar el papel protagónico que podía atribuírsele a los indios/mistis, mejor dicho, a los clásicos protagonistas del indigenismo salvo en el caso de las narraciones que, probablemente, eran proyectos que más tarde concurrirían en el texto fundacional Los ríos profundos (1958).

Sigamos pues el original camino de Arguedas reconociendo que asume por primera vez una enunciación sobre el mestizo en el ensayo Canto kechwa de 1938, una introducción a la breve antología bilingüe de poesía y canto quechua. Fue una recopilación considerada la traducción de material lírico de los valles del Apurímac que se publica antes de Yawar Fiesta (1941). En este trabajo pionero explica dos ideas rectoras de un pensamiento en constante efervescencia: la capacidad del indio para expresar sus sentimientos a través de un lenguaje poético y la entrañable relación con el mestizo para recrear el arte indígena (canto, música, artesanía):

La mayoría del pueblo racialmente mestizo se mantiene indio en costumbres y por su condición social; su vida es indígena en todas sus manifestaciones, y a todos se les denomina indios. Es, pues, cierto que el pueblo indio constituye mayoría en el Perú. [...] Los mestizos propiamente dichos - medios mistis, taksa K'alas, chalos- constituyen en la sierra del Perú un estado social superior a la del indio, aunque no en todos los casos su condición económica sea mejor. La expresión artística del mestizo es de la más pura ascendencia indígena. [...] En el pueblo mestizo tiene mucho mayor dominio el elemento indio. Es que además de la influencia racial y del ambiente, en las relaciones de la vida diaria, de la vida en todos sus aspectos, el mestizo está mucho más cerca del indio (1989a, pp. 13-15).

El pasaje revela una determinación juvenil con la cual Arguedas expresa su posición a favor de la unidad entre el indio y el mestizo, lejano de crear una alianza del mestizo a los «medios mistis» que imitaban los terratenientes. Una idea avanzada hecha cuando tenía 27 años que debió interrumpir sus estudios universitarios después de ser encarcelado y vivir como profesor de escuela, ya casado y auto-exilado. Por esto, no sorprende la lúcida y madura declaración autorreferencial sobre la innegable cercanía de 
quienes viven «mucho más cerca del indio» $\mathrm{y}$ «aunque lo nieguen [...] encuentran en el arte indio la expresión de sus sentimientos más hondos y propios», especialmente en lo que llama pueblos y ciudades grandes; en ese sentido, sentencia:

el día en que el mismo pueblo indígena sea dueño de su propio destino, y dueño entonces de medios de expresión superiores y suficientes, ese día, en el Perú, pleno de juventud, se desarrollará vigorosamente el arte, obra y expresión del mestizo y del indio, libre ya de los obstáculos que la inferioridad social le imponen ahora (ibíd., p. 20).

Esa visión positiva del creador artístico en el Perú hace ver el crecimiento del autor comprometido, cuando empieza a reivindicar los valores andinos, asociando necesariamente los indios a los mestizos. Individuos históricos en los que deposita tanto el interés cultural como una profunda comprensión étnico-lingüística que será retomada en el prolífico decenio de los años cincuenta, en base al ideal estético y espiritual del pueblo que logra mejorar sin abandonar sus raíces, a pesar del estigma imputable a sus denigradores por «sus características raciales» (Arguedas, ibíd.). Es útil subrayar el elemento racial ya que entrevé una fina línea interpretativa, aunque limitada, sobre la raza y el regionalismo. En relación con este período y, en particular con Yawar Fiesta, Cornejo Polar reconoce que es el «primer gran esfuerzo» literario que, transparentemente, «reivindica los valores de la cultura andina proponiéndolos como la fuente de la nacionalidad y como raíz de un arte, sea peruano que universal» (1996, p. 53).

La segunda vez que Arguedas reflexiona agudamente sobre el mestizo es en el artículo «Entre el kechwa y el castellano, la angustia del mestizo» (1939) en relación al conflicto que encontraba entre la expresión de su mundo interior y el idioma castellano. Allí se refiere a la «angustia del mestizo», sin reflexionar en primera persona sobre su origen social y formación, aparte del amor al mundo indígena y al quechua. Con todo existe un paralelo autobiográfico entre su condición de mestizo y las figuras de los cuentos y novelas de ese período que todavía corresponde a sus primeros relatos. Igualmente en ese ensayo se celebra el valor del quechua, idioma que custodia auténticamente la herencia andina que, entre los actores sociales subalternos, sólo el mestizo habría hecho conscientemente propia. Por esta razón,

en casi todo el período republicano se mantuvo al mestizo en la misma condición de inferioridad y de silencio que tuvo durante la Colonia. Es por esta causa que ni en la literatura de la Colonia ni en la de los primeros tiempos de la República se encuentra ninguna obra de verdadero valor como expresión del pueblo andino y el paisaje en que vive. Pero los mestizos siguieron aumentando en número y en cultura y llegaron a ser el pueblo, mayoría en el Ande del Perú como ciudadanos y como espíritu (2009, pp. 141-144).

Sin embargo, puede afirmarse que es través de una suerte de superposiciones que llega a obtener esta claridad, cuando su interpretación alcanza una enunciación importante y, poco a poco, dice que, además de los mismos indígenas, los mestizos ostentan una irrebatible capacidad para la literatura. No es difícil entender que el punto de madurez lo alcanza en los trabajos antropológicos y folclóricos, después de terminar sus estudios de etnología en San Marcos (1957) ${ }^{9}$ y cuando ya había comenzado la segunda etapa de su producción literaria, es decir, la escritura empezada con El Sexto (1961) y seguida de novelas, cuentos y poesía en las que asume definitivamente la narración totalizadora que reclamó factible y modesta en la famosa Mesa redonda de 1965.

Una percepción disonante y menos positiva a esta progresión apenas citada se vislumbra en el artículo «La novela y el problema de la expresión literaria en el Perú» de 1950, en el cual vuelve a analizar Yawar Fiesta (2009, pp. 153-160). Allí discute el papel subordinado que atribuye a la figura del mestizo y al espacio semántico que alcanzaba el personaje en aquel periodo en su narración. Es en este artículo donde deslinda el porqué no la consideraba una opera indigenista sino una novela mayor ligada al «pueblo grande» que, más tarde, veremos completado en la combinación ciudad/país donde convergen los hombres y mujeres migrantes de la Sierra adentro. Refiriéndose a sus personajes hizo una especie de retrospección:

el mestizo de pueblo que en la mayoría de los casos no sabe adonde va; sirve a los terratenientes y actúa ferozmente contra el indio, o se hunde en la multitud, bulle en ella para azuzarla y descargar su
Comienza la universidad en 1931 pero interrumpe los estudios por la muerte de su padre y su encarcelamiento en el Sexto. Define su vocación profesional después de trabajar como etnólogo, titulándose tardíamente. 
agresividad o se identifica con el indio, lo ama o sacrifica generosamente su vida por defenderlo (2009, pp. 153-160).

No obstante, Arguedas advierte el espacio aislado del mestizo que hasta entonces no tenía salida frente a "ese mundo feroz» protagonizado por los indios/mistis desde los cuentos de Agua hasta antes de la novela Yawar Fiesta. Puede huir de ese microcosmos por medio de la migración a la ciudad o asumir la salida que sólo «uno de mil escoge»: erguirse contra los indios y los mistis y «meterse como una cuña entre ellos». En efecto,

En estos tiempos prefieren irse; llegar a Lima, mantenerse en la capital a costa de los más duros sacrificios; siempre será mejor que convertirse en capataz del terrateniente, y, bajo el silencio de los cielos altísimos, sufrir el odio extenso de los indios y el desprecio igualmente mancillante del dueño. Existe otra alternativa que sólo uno de mil la escoge. La lucha es feroz en esos mundos, más que en otros donde también es feroz. Erguirse entonces contra indios y terratenientes; meterse como una cuña entre ellos; engañar al terrateniente, afilando el ingenio hasta lo inverosímil y sangrar a los indios (2009, p. 156).

Es una conclusión desconcertante, que cristaliza la dificultad de alterar el equilibrio social que, según Arguedas, se había vuelto crónica. Indudablemente no lo podrá hacer ninguno de los dos estereotipos de mestizo narrado hasta ese momento, no lo hubiera podido hacer ni el «disimulado» ni el «inclemente» que aún actuaba con odio (ibíd.). $\mathrm{Me}$ parece estar frente a una memoria arguediana autocrítica, quizá nutrida de nuevas hipótesis antropológicas sobre el cambio social, pero que refiriéndose a sus textos encuentra plasmada una percepción que, más tarde, modificará con la búsqueda del «estilo» universal.

Comparados ambos comentarios, que dis$\tan$ de once años, es evidente que en su pensamiento la condición histórica del mestizo es una cuestión esencial sobre la cual no existía una salida única. Por una parte su figura literaria puede proyectarse como defensora de los indios de la Sierra y, por otra, de servidor de los mistis o terratenientes. Pero señala no circunscribirlo, ya que esa figura le confería la posibilidad de optar dada su naturaleza interpuesta.
En la base del discurso ficcional arguediano del primer período quedaba fija la relación entre mistis e indios, a veces míticos y otras verdaderos y, en todo caso, intérpretes de un mundo antagonista y cerrado. Como Flores Galindo observa: «de un lado está lo positivo y, de otro, lo negativo. Es una relación donde sólo existía la violencia. Los indios hablan entre indios y los mistis entre mistis. Pero hay comunicación entre indios y mistis. Y si hablan es sólo para agredirse, para insultarse. [...] Nunca hay un nivel de comunicación, siempre está de por medio la mentira, el engaño, cuyo origen está en el poder de los mestizos sobre los indios» (1992, p. 19). Todavía Arguedas volvía a sus primeras opiniones que indicaban el camino que tendría que recorrer, asociándolos secamente a los mistis ya que «eran los señores blancos o mestizos, en todo caso, los que mandan y tienen poder, mejor dicho, los propietarios de haciendas o autoridades políticas que necesitaban del trabajo de los indios "para poder vivir» (Flores Galindo, 1988, p. 350). Desenlace congruente que considera también los retrocesos del mundo dividido y relacionado sobre todo a la ficción, en la que «los mestizos se reducen al alma individual» (ibíd., p. 353).

Una idea que poco a poco Arguedas cambiará en la hechura de sus trabajos literarios y antropológicos a partir de la frontera de Los ríos profundos, en la mayoría de los cuales dejará de registrar la relación de sujeción y atadura del mestizo. Así invertirá la visión predispuesta a la vulnerabilidad del mestizo por una resuelta valoración de las potencialidades artísticas para luego profundizarla en el conflicto por el dominio de esa humanidad «total» desde El Sexto y Todas las Sangres (1964) hasta los últimos hervores míticos de los zorros (Melis, 1990). Novelas, poesías y ensayos donde el diálogo con los interlocutores le dará resultados de gran alcance para la cultura regional y, a la vez, para la crítica criolla.

$\mathrm{Y}$, sin embargo, las dificultades que encuentra en el mestizaje histórico no son sino el anuncio de la dificultad de la construcción identitaria en un Perú en el que por sucesivas aproximaciones se irían fusionando el mundo andino y el occidental. Una modificación de los factores y problemáticas en juego que Arguedas trata de interpretar, apoyándose en convicciones positivas y en un cambio radical de enfoque, ilustrativo del reto que asumió: 
«la integración nacional, vía el mestizaje, desaparecerá virtualmente en la producción de sus últimos años» como sostiene Nelson Manrique, quien lo relaciona a

su condición de creador literario, que le permitió no renunciar a su intuición, su sensibilidad y su afectividad, elementos reñidos con una concepción positivista del «trabajo científico» que exige poner entre paréntesis la subjetividad, como garantía de objetividad para acercarse a la realidad, [imposible] en un país tan desafiante a nivel teórico como es el Perú (1995).

\section{La convivencia del mestizo de la ficción y el histórico}

El primero lo ha construido en base a su vivencia directa, en la que pesa su infancia y juventud, es decir, las experiencias de vida en las fronteras del pequeño y grande pueblo donde convivía el mestizo. El segundo distingue en el mestizo su capacidad creadora y artística, así también una inserción posible en la economía de la costa y de las ciudades. Como he referido, a esta figura que habla quechua y español y ha ido al colegio se le atribuye una posición incierta y, por consiguiente, se ve obligado a partir, dejando su mundo de sabiduría ancestral ${ }^{10}$ para integrarse, no sin dificultad, en las ciudades.

Esta lógica en relación a los espacios de la creación ficcional y del análisis etnológico comprueba la presencia constante del personaje histórico y también permite identificar diferentes planos de la participación del mestizo en esa realidad continua donde es básica su experiencia. Ello muestra asimismo imágenes delineadas a partir de un comportamiento estereotipado, nutrido de los dilemas a él asignados en la mayor parte de su literatura, donde se ven también las expectativas sobre el modo como podrá sobrevivir el mestizo en la sociedad nacional.

Ello subraya la fuerza de ciertas imágenes de las vivencias del mestizo promovida desde el imaginario ficcional antes que del mismo análisis antropológico. En efecto, bien sabemos que Arguedas entiende el mundo interior del mestizo y lo proyecta en sus narraciones no sin darle su propia apreciación, mientras conoce también el espacio externo y popular de los mestizos en el cual media su formación en las disciplinas sociales, como lo ejemplifica en la fuerza magistral de la lengua del quechua y de la oralidad para la expresión artística y el catolicismo andino, antes que nada indígena y luego mestiza. Este es el cuadro central que funciona como espacio asociado al mestizo, colocado como alteridad conflictiva por su potencial ambigüedad o doblez en el escenario principal de la literatura peruana de entonces. A este punto, esta figura ficcional e histórica transita el espacio existencial arguediano para volverse creativo, remontando desde el pasado y, más adelante, siendo congruente con su visión antropológica, para alcanzar todavía un presente precario seguramente frágil. Y así, no sólo afirmar idealmente los valores prehispánicos (Cornejo Polar, 1989, p. 125) resguardados en los Andes, sino refundar con ese patrimonio un discurso humano y de fe en el porvenir de los explotados (Lévano, 2011, p. 20) y de maestro de una peruanidad venidera.

En la ficción de Arguedas, el mestizaje podía integrar a los indígenas que se separaban del mundo tradicional y se convertían en un tipo de personaje oscilante que, desde la escuela, pasaba a vivir a la ciudad para ser un probable defensor de los indios o su contrario. Es una posición de aparente esquematismo, por la cual los mestizos no habrían tenido muchas escapatorias a despecho de las diferentes vías de acceso a una cultura nacional fácil objeto de la propaganda de la «ideología salvífica del mestizaje» (Cornejo Polar, 1997, p. 268). Hay que recordar que en el Perú de los años cincuenta y sesenta, los mestizos no respondían a la integración que se anunciaba como opción ineluctable y entonces presentaban destinos discrepantes a los asumidos en las ficciones arguedianas. Sin embargo, la fuerza de su imaginación literaria no se puede explicar cabalmente ${ }^{11}$. Existen varios matices o variaciones antes que maniqueísmo o divergencias en su narración antropológica.

A continuación señalo algunas sugerencias del tema de la gestación de imágenes del mestizo en Arguedas, a modo de enunciación mínima:

- ser mestizo significa participar al lado del indio o del señor misti, no obstante, puede romperse esta atadura cuando se deja el pueblo y la provincia;
10

Se soslaya la llamada «sabiduría tradicional» que, según Arguedas, servía en principio para rescatar prácticas culturales de origen indígena, pero que era un instrumento para entender esa otra humanidad (1986, p. 81).

11

La desilusión de Arguedas frente a la polémica de la Mesa redonda de 1965 sobre Todas las sangres le hizo decir una incisiva frase aparentemente absurda contra los doctores allí reunidos: "el quechua será inmortal, amigos de esta noche. $Y$ eso no se mastica, sólo se habla y se oye» (VV.AA., 1985, p. 68). 


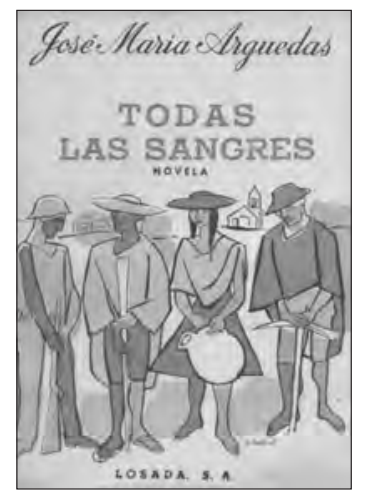

12

Una posición que veía en este mestizaje la solución a los problemas de la población indígena (Manrique, 1995). La operación descansaba en una propuesta en la que centralmente aparecía la personalidad y obra mítica de Inca Garcilaso, defensor de una construcción identitaria (Salazar, 2010 , p. 148).
La gestación de imágenes del mestizo en el pensamiento arguediano

CARLOS MIGUEL SALAZAR
- el mundo de la migración introduce al mestizo en una sociedad donde domina la cultura costeña que rechaza lo serrano y es motivo de discriminación y racismo;

- el agrupamiento de los mestizos es factible entenderlo como una reunión donde la adhesión es individual y, tal vez, una categoría pero no una clase social;

- la figura del mestizo se conecta automáticamente a la relación potencial frente a la oposición indios/mistis instaurada en el contexto rural;

- la condición de mediador pronto a la defensa de las raíces culturales se contrapone a la del sujeto cuyo destino es la ocupación en un sistema productivo inicuo;

- la migración se realiza según un modelo de integración desarrollista que da pié a la pérdida o renuncia de las raíces culturales a comenzar por el idioma;

- los mestizos se convierten a la vida moderna, mientras que los indígenas quedan anclados en la explotación y pobreza, fuera de la mano del estado;

- el sujeto migrante reactiva su vida tradicional en la ciudad y plasma las formas de reciprocidad comunal, culto y religiosidad popular;

- la cultura andina puede ser conquistada y fragmentada pero no abate ni su organización social ni el sistema cultural por la vitalidad del legado ancestral.

A través de su narración ficcional y antropológica el autor andahuaylino advierte que la presencia del personaje mestizo es importante en el cuestionamiento de la hegemonía «hispanista» y «criolla», donde prevalecía la dominación colonial y semifeudal. Por ello ilumina la existencia del mestizo ficcional e histórico desde las más recónditas comunidades hasta las más prósperas áreas serranas o desde la célebre Huamanga hasta los grandes museos.

La creación discursiva de Arguedas anuncia una percepción sobre una humanidad que sirve para construir el camino de las fronteras permeables y de los hervores premonitorios. Mejor dicho, una vía que sólo él percibe a través de su sensibilidad artística, dando aliento a su obra sobre el encuentro/desencuentro fundado en la mitología y la comunicación bilingüe. Una lectura transcultural elaborada desde una de sus fuentes inspiradoras que es el imaginario andino que recurre con empeño a los varios lugares simbólicos de la construcción identitaria y de la hibridación cultural (territorio, lengua, imaginería, religiosidad).

Por tanto, en la propuesta de Arguedas funciona una visión abierta de la figura del mestizo. Sus figuras retornan como personajes populares e identificados con la naturaleza, la lengua y los indios, sabiéndose desenvolver entre las dos racionalidades e intereses. Una opción llega hibridada de la cosmovisión andina y la otra es un producto ecléctico e imitador de los propietarios. Una vez más, sus personajes consiguen hacer emerger una realidad sociocultural compleja y testimonian la interculturalidad del "país más diverso».

Si bien es cierto que Arguedas se preguntaba si el mestizo habría actuado a favor del pueblo o si habría colaborado con los comuneros sin alterar el esquema de explotación, la respuesta de la ficción correspondía a la realidad. Lo demuestra en sus dos últimos textos, especialmente en Todas las Sangres (1964) cuando piensa la identidad intermedia del comunero Demetrio Rendón Willka, dejando atrás su idea sobre la ambigüedad de este «héroe civilizador». Un mestizo que obra entre la autenticidad y el disimulo, como lo demuestra la narración que frente a la represión introduce el liderazgo legendario y la rebeldía que alcanza el sacrificio extremo (Cornejo Polar, 1997, p. 213). Asimismo, según el mismo Arguedas, la conversión de un indio en imagen mítica (VV.AA., p. 28) o, más bien, en figura histórica según la racionalidad sagrada de los Andes para suprimir la explotación indígena.

A veces nos olvidamos que en esos años existía una perspectiva criolla que idealizaba hasta volverla popular la idea de un mestiza$j e^{12}$. En aquel tiempo se imaginaba este proceso como una solución salvadora frente a las distancias sociales y raciales que entonces no se cubrían con el ropaje del espejismo étnico. Olvidándose que antes se trataba de entender al mestizo como identidad colectiva -a diferencia de Arguedas que pensó al mestizo como individualidad- y como convergencia de razas, culturas, regiones y lenguas. Una síntesis ideal para frenar la idea de los rasgos atávicos presentes en la construcción de una peruanidad que tenía la necesidad de la aculturación y del mestizaje, según el paradigma culturalista, llano a adaptarse a la cancelación 
del aislamiento de las zonas rurales y hacer funcional el sistema.

Con la gestación de imágenes del mestizo Arguedas afronta su propia versión del mestizaje, considerándola una realidad emergente para la transformación social. Su experiencia de vida le hace entender la validez de la construcción ficcional de dicho personaje, en cuanto apoyo al objetivo indispensable de la resistencia a la integración si se conservaba el dualismo arcaico. Pero, al mismo tiempo, percibía en esa figura ficcional la dificultad para abstraerla unívocamente. Estoy convencido de que su interés por el personaje se basa en la vinculación al universo indígena, el cual daba pie a que apareciese una figura histórica y generadora de esperanza para acabar con la servidumbre y la pobreza. La figura del mestizo se volvía, por esto, indispensable para la reelaboración imaginaria del mundo rural andino frente a una modernidad que irrumpía impetuosamente y que hacía necesaria la intermediación de éste.

\section{Bibliografía}

Arguedas, José María (1973), El zorro de arriba y el zorro de abajo, Losada, Buenos Aires.

Arguedas, José María (1981), Formación de una cultura nacional indoamericana (antología de Ángel Rama, [1975]), México, Siglo XXI.

Arguedas, José María (1986), “¿Qué es el folklore?» [1964-1965], en Breve Antología Didáctica, Lima, Horizonte.

Arguedas, José María (1989a), Canto kechwa. Con un ensayo sobre la capacidad de creación artística del pueblo indio y mestizo [1938], Lima, Horizonte.

Arguedas, José María (1989b), «El indigenismo en el Perú» (1965), en Indios, mestizos y señores, Lima, Horizonte.

Arguedas, José María (2009), Qepa Wiñaq, Siempre literatura y antropología, Madrid, Iberoamericana-Vervuert.

Callirgos, José Carlos (1993), El racismo. La cuestión del otro (y de uno), Lima, Desco.

Cornejo Polar, Antonio (1989), La formación de la tradición literaria en el Perú, Lima, CEP.

Cornejo Polar, Antonio (1996), José María Arguedas. Antología comentada, Lima, Biblioteca Básica Peruana.
Cornejo Polar, Antonio (1997), Los universos narrativos de José María Arguedas, Lima, Horizonte.

Del Pino, Fermín (2005), «Arguedas como escritor y antropólogo", en Carmen Pinilla y otros (ed.), Arguedas y el Perú de hoy, Lima, Sur-Casa de Estudios del Socialismo, pp. 377-403.

Fell, Eve-Marie (1991), «Arguedas y Huancayo; hacia un nuevo modelo mestizo», en Roland Forgues y otros (ed.), José María Arguedas. Vida y obra, Lima, Amaru editores, pp. 85-95.

Flores Galindo, Alberto (1988), Buscando un inca, Horizonte, Lima, Horizonte.

Flores Galindo, Alberto (1992), Dos ensayos sobre J. M. Arguedas, Lima, Sur-Casa de Estudios del Socialismo.

Forgues, Roland (2004), J. M. Arguedas. De la pensée dialectique à la pensée tragique. Histoire d'une utopie, Toulouse, Presses Universitaires du Mirail.

González Vigil, Ricardo (2000), «Introducción», en José María Arguedas, Los ríos profundos, Madrid, Cátedra, pp. 9-108.

Lévano, César (2011), Arguedas. Un sentimiento trágico de la vida, Lima, Fondo de la UIGV.

Lienhard, Martín (1992), La voz y su buella, Lima, Horizonte.

López Maguiña, Santiago y Portocarrero, Gonzalo (2004), «El pongo dentro de mí», Quehacer, n. 147, pp. 106-113.

Manrique, Nelson (1995), «José María Arguedas y la cuestión del mestizaje», en Maruja Martínez y Nelson Manrique (ed.), Amor y fuego. José María Arguedas 25 años después, Lima, Desco-Cepes-Sur, pp. 77-89.

Melis, Antonio (1990), «L'ultima sfida di Arguedas: dare voce al caos e all'afasia» (Introducción y notas a la traducción), en José María Arguedas, La volpe di sopra e la volpe di sotto, Turín, Einaudi, pp. V-XVIII.

Pinilla, Carmen María (1993), «El principio y el fin: Mariátegui y Arguedas», Anuario Mariateguiano, V: 5, pp. 45-57.

Portocarrero, Gonzalo (2005), «Lucha por la descolonización sin rabia ni vergüenza», en Carmen Pinilla y otros (ed.), Arguedas y el Perú de hoy, Lima, Sur-Casa de Estudios del Socialismo, pp. 25-42.

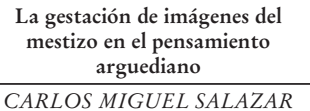

CARLOS MIGUEL SALAZAR 
Rivera, Fernando (2011), Dar la palabra. Ética, política y poética de la escritura en Arguedas, Madrid, Iberoamericana, Vervuert.

Rivera, Juan Javier (2002), «Una antropología del mestizaje. El concepto de cambio cultural en la obra de Arguedas y en la crítica al paradigma indigenista», Anthropologica, XX: 20, pp. 77-102.

Rovira, José Carlos (2001), «José María Arguedas y la memoria autobiográfica del indigenismo contemporáneo", Anales de Literatura Española, 14, pp. 187-199.

Rowe, William (1996), Ensayos arguedianos, Lima, UNMSM y Sur-Casa de Estudios del Socialismo.
Salazar, Carlos Miguel (2006), «¿Comentarios reales o inventados? Los profesores cuzqueños tienen la palabra», Crónicas Urbanas (Cuzco), X: 11, pp. 101-110.

Salazar, Carlos Miguel (2010), Frammenti andini. Gli insegnanti di Cuzco reinventano un'identità nazionale, Roma, Centro d'Informazione e Stampa Universitaria.

VV.AA. (1985), ¿ He vivido en vano? Mesa redonda sobre Todas las sangres. 23 de junio de 1965, Lima, IEP.

Fecha de recepción: 30/06/2012

Fecha de aceptación: 22/10/2012
La gestación de imágenes del mestizo en el pensamiento arguediano 